\title{
Soil Inoculum Production, Survival, and Infectivity of the Boxwood Blight Pathogen, Calonectria pseudonaviculata
}

Norm Dart, Department of Plant Pathology, Physiology and Weed Science, Virginia Polytechnic Institute and State University, Blacksburg 24061; Chuanxue Hong, Hampton Roads Agricultural Research and Experimental Station, Virginia Tech, Virginia Beach 23455; Caryn Allen Craig, Virginia Department of Agriculture and Consumer Services, Office of Plant Industry Services, Richmond 23219; and J. T. Fry and Xinran Hu, Department of Statistics, Virginia Polytechnic Institute and State University, Blacksburg

\begin{abstract}
Dart, N., Hong, C., Craig, C. A., Fry, J. T., and Hu, X. 2015. Soil inoculum production, survival and infectivity of the boxwood blight pathogen, Calonectria pseudonaviculata. Plant Dis. 99:1689-1694.

Boxwood blight caused by Calonectria pseudonaviculata is typically expressed as a foliage disease with aboveground symptoms including defoliation, dieback and formation of dark narrow stem cankers. Whether this pathogen behaves like other Calonectria spp. and has a significant soil phase in the epidemiology of boxwood blight is not known. In this study we observed experimentally that (1) the boxwood blight pathogen consistently forms microsclerotia in artificially inoculated leaves and roots of

Buxus spp., (2) soil artificially inoculated with conidia and microsclerotia of this pathogen can cause foliar blight, (3) conidia and microsclerotia can remain viable in soil for up to 3 and at least 40 weeks, respectively (4) and the pathogen can cause crown and root rot to plants only when roots and crowns are directly exposed to relatively high inoculum levels. Our results suggest that $C$. pseudonaviculata is primarily a foliar pathogen with a potentially epidemiologically significant soil phase.
\end{abstract}

Boxwood blight, caused by Calonectria pseudonaviculata (Crous, J. Z. Groenewald \& C. F. Hill) L. Lombard, M. J. Wingf. \& Crous (syns. Cylindrocladium pseudonaviculatum Crous, J. Z. Groenewald $\&$ C. F. Hill and C. buxicola Henricot) (Henricot and Culham 2002) was first described in the United Kingdom in the mid-1990s and, by 2002, had spread to several other European countries and New Zealand (Henricot et al. 2008). In September 2011, boxwood blight was reported for the first time in North America (Ivors et al. 2012). The disease is expressed as aboveground symptoms, including leaf spotting, defoliation, formation of narrow long dark cankers, and dieback. Previous work has focused on controlling the aerial phase of boxwood blight using host resistance and fungicides (Henricot et al. 2008).

Many Calonectria spp. that cause foliar and shoot blight also have an epidemiologically significant soil phase (Black and Beute 1985; Gonçalves et al. 2001; Hwang and Ko 1976; Kuruppu et al. 2004; Linderman 1972, 1973; Phipps et al. 1976; Rowe et al. 1974; Sobers and Littrell 1974; Thies and Patton 1970), yet relatively little research has been done to understand the potential significance of the soil phase of the boxwood blight pathogen. No experimental work has previously looked at the ability of soilborne inoculum to persist and infect foliage and roots once introduced to soil. Results from one study reported the ability of the pathogen to persist in decomposing leaf debris in soil for 4 years (Henricot et al. 2008); a second study documented that the pathogen forms microsclerotia in host leaves and stems (Dart et al. 2012; Weeda and Dart 2012). Microsclerotia are resting propagules that allow pathogens to persist in soil and cause subsequent disease to host plants (Crous 2002). Taken together; these previous findings suggest that, like other Calonectria spp., Calonectria pseudonaviculata may have an epidemiologically significant soil phase. Understanding the potential role of soil inoculum in the epidemiology of boxwood blight will be crucial for developing effective best-management practices for growers, landscape professionals, and homeowners. To better understand the potential role of

Corresponding author: N. Dart; E-mail: norman.dart@vdacs.virginia.gov

Accepted for publication 30 March 2015.

http://dx.doi.org/10.1094/PDIS-12-14-1245-RE

(C) 2015 The American Phytopathological Society the soil phase of $C$. pseudonaviculata, we conducted experiments to determine (i) the extent to which C. pseudonaviculata forms microsclerotia in the leaf and root tissue of Buxus spp., (ii) whether soil infested with microsclerotia and conidia can cause foliar blight, (iii) the relative length of time microsclerotia and conidia remain viable in soil, (iv) and whether C. pseudonaviculata can cause root and crown rot to Buxus spp.

\section{Materials and Methods}

Soil, conidia, and microsclerotia production. A Suffolk sandy loam ( $\mathrm{pH}$ 6.0) was collected from a boxwood nursery located in the Coastal Plains of Virginia. The nursery had no known history of boxwood blight; collected soil was assayed for C. pseudonaviculata using a leaf disc bioassay (Dart et al. 2014; Gonçalves et al. 2001) and the pathogen was not detected. The soil was stored at room temperature ( 22 to $24^{\circ} \mathrm{C}$ ) in 18.9-liter plastic buckets. Prior to use, soil was sifted through an 850- $\mu \mathrm{m}$ sieve, then mixed by hand.

A single-conidium isolate of $C$. pseudonaviculata obtained from an infected Buxus sempervirens 'Arborescens' plant at a nursery in Carroll County, VA was used in this study. Microsclerotia were produced by growing the fungus on potato dextrose agar for 8 to 12 weeks, then harvested and enumerated as previously described (Dart et al. 2014). Microsclerotia used for experiments were $100 \%$ viable as determined by counting the proportion of microsclerotia that germinated on acidified peptone-dextrose agar (PEDA) after 10 days (Hwang and Ko 1975, 1976). Conidia were obtained by growing the fungus on potato dextrose agar for 8 to 12 weeks, stimulating conidia formation, and then harvesting. To stimulate conidial formation, plates were flooded with 4 to $5 \mathrm{~mm}$ of deionized water (DI) for $2 \mathrm{~h}$, then scraped with a curved glass rod. Loose mycelium was rinsed off the agar by gently flooding the plates with 4 to $5 \mathrm{~mm}$ of DI water, swirling the water in the plates, and decanting. After rinsing four to five times, excess water was poured off and the plates were incubated at 22 to $24^{\circ} \mathrm{C}$ in ambient light for 4 days. Freshly formed conidia were harvested by flooding the plates with 4 to $5 \mathrm{~mm}$ of DI water and gently swirling the plate to help conidia release. The water containing the conidia was then decanted into a beaker, resulting in 10 to $20 \mathrm{ml}$ of conidial suspension. The spore suspension was then shaken vigorously in a 50-ml Falcon tube to mix the suspension and break up conidia that were stuck together. The conidia were enumerated by pipetting 1 to $2 \mu \mathrm{l}$ of conidial suspension onto a glass slide and counting with the aid of a compound microscope. 
Microsclerotia formation in leaf and root tissue of Buxus spp. Cuttings of B. sempervirens Arborescens, B. sempervirens 'Suffruticosa', B. microphylla 'Winter Gem', and B. sempervirens $\times B$. microphylla 'Green Mountain' ( 8 to $12 \mathrm{~cm}$ in length) were inoculated by spraying with a conidial suspension $(10,000 / \mathrm{ml})$ until run-off; DI water was applied to controls. Five cuttings of each cultivar were stuck upright in flats of sand saturated with water, and covered with plastic bags to maintain humidity for the inoculated and control treatments. The cuttings were incubated in a growth chamber at $25^{\circ} \mathrm{C}$ with $12 \mathrm{~h}$ of light. The presence and relative abundance of microsclerotia were measured weekly in the leaf tissue of each cultivar for 4 weeks. This was done by arbitrarily harvesting 7 to 10 leaves from each treatment every 7 days and clearing them in $5 \% \mathrm{NaOH}$ for 5 to 7 days (Linderman 1972). The microsclerotia were counted in three arbitrarily chosen $1-\mathrm{mm}^{2}$ plots of each leaf using a compound microscope. The average numbers of microsclerotia for each cultivar were plotted over time. The experiment was repeated once.

Roots were sampled in October 2013 from 50 B. sempervirens Arborescens boxwood plants in three nursery fields in Carroll County, VA with aboveground blight symptoms and checked for infection by C. pseudonaviculata. The plants had been in the ground for between 1 and 3 years and were approximately 30 to $60 \mathrm{~mm}$ tall. Root samples were dug from the upper $6 \mathrm{~cm}$ of soil, and 20 arbitrarily chosen root segments from each plant were cut into $4-$ to 6 -cm segments. The root segments were surface sterilized in $0.25 \% \mathrm{NaOCl}$ for $30 \mathrm{~s}$, rinsed under a stream of water for $30 \mathrm{~s}$, and plated onto PEDA. The roots were then incubated at 22 to $24^{\circ} \mathrm{C}$ in ambient light and evaluated at 7 and 14 days for sporulation of $C$. pseudonaviculata with the aid of a dissecting microscope. Root systems of rooted Buxus spp. were also inoculated with C. pseudonaviculata and processed as described below. Roots that were symptomatic or determined infected based on sporulation of $C$. pseudonaviculata were stained by boiling in lactoglycerol (1:1:1, lactic acid/glycerol/distilled water) with $0.05 \%$ trypan blue for $30 \mathrm{~s}$ in a microwave. Tissue was cleared for $24 \mathrm{~h}$ in $1: 1$ glycerol/distilled water (Weeda and Dart 2012). Once cleared, root tissue was viewed and inspected for microsclerotia with the aid of a compound microscope.

Ability of infested soil to cause foliar infection. Soil was infested with conidia at 10,100,1,000, and 10,000 conidia/g and microsclerotia at 25, 50, 100, and $200 \mathrm{microsclerotia/g}$. Conidia $(10 \mathrm{ml})$ at concentrations of $100,1000,10,000$, and 100,000 conidia/ml and microsclerotia $(10 \mathrm{ml})$ at 250, 500, 1,000, and 2,000 microsclerotia microsclerotia/ml were added to $100 \mathrm{~g}$ of air-dried soil. Uninoculated soil was used for controls. Soil moisture was adjusted to $30 \%$ (wt/wt) and the soil was mixed thoroughly. For each treatment, four unrooted cuttings of $B$. sempervirens Arborescens ( 8 to $12 \mathrm{~cm}$ in length) were evenly coated with soil by lightly blotting against soil. Cuttings were then placed upright in 150-ml beakers with $2 \mathrm{~cm}$ of water in the bottom and covered with plastic bags to maintain humidity. Three replicates were used for each treatment. Cuttings were incubated in a growth chamber at $25^{\circ} \mathrm{C}$ with $12 \mathrm{~h}$ of light. Proportion of blighted leaves was recorded at 7 days and infection by $C$. pseudonaviculata was confirmed by examining leaves for conidiophores bearing conidia and vesicles of $C$. pseudonaviculata with the aid of a dissecting microscope. The experiment was repeated once.

Survival of microsclerotia and conidia in soil. Conidia $(10,000$ conidia/g) and microsclerotia (100 microsclerotia/g) were mixed separately with a Suffolk sandy-loam soil in 700-ml plastic containers in 100 -g (dry weight [dw]) aliquots. Soil was infested by adding $10 \mathrm{ml}$ of conidial suspension at a concentration of 100,000 conidia/ml, and $10 \mathrm{ml}$ of microsclerotia at $1,000 \mathrm{microsclerotia} / \mathrm{ml}$ to $100 \mathrm{~g}$ of airdried soil. Uninoculated soil was used for controls. Soil moisture was adjusted to $30 \%$ (wt/wt) and containers were covered with a plastic lid. Soil moisture was maintained by periodically adding water. The infested soil was incubated at 22 to $24^{\circ} \mathrm{C}$ in ambient light. The relative viability of inocula in the soil was quantified using a leaf disc bioassay (Dart et al. 2014; Gonçalves et al. 2001). This was done by placing 10 B. sempervirens Arborescens leaf discs $(5.5 \mathrm{~mm}$ in diameter) directly on the soil surface of the infested and control treatments to bait the pathogen for $96 \mathrm{~h}$. After incubation with soil, leaf discs were removed, surface sterilized in $0.25 \% \mathrm{NaOCl}$ for $30 \mathrm{~s}$, rinsed under a stream of water for $30 \mathrm{~s}$, and plated onto PEDA. Isolation plates were incubated at 22 to $24^{\circ} \mathrm{C}$ in ambient light for 7 to 10 days, at which time individual baits were evaluated for sporulation by C. pseudonaviculata using a dissecting microscope. A leaf disc was considered infected by $C$. pseudonaviculata if pathogen sporulation was observed. Percent infected leaf discs were plotted over time. The leaf disc bioassay was conducted on the infested soil every week for the first 2 months of the experiment and then every 1 to 2 months for 40 weeks or until C. pseudonaviculata could not be recovered. The experiment was completed in replicates of three and was repeated once.

Potential for $C$. pseudonaviculata to cause root and crown rot. Two experiments were conducted to test the ability of $C$. pseudonaviculata to cause root and crown rot. These included inoculating seedlings by dipping roots into a suspension of conidia and by drenching rooted cuttings with a suspension of conidia while they remained in potting mix.

To inoculate rooted cuttings by dipping, cuttings of $B$. sempervirens Arborescens, B. microphylla Winter Gem, B. harlandii, and B. sinica var. insularis 'Wintergreen' (6 to $8 \mathrm{~cm}$ in length) were rooted in flats (standard 1020 size) containing 50 round cells . One cutting was rooted per cell in $20 \mathrm{~g}(\mathrm{dw})$ of sand and peat mix (1:1) for 12 to 14 weeks. The roots were inoculated by taking them out of the sand peat mix, rinsing them in running tap water for $30 \mathrm{~s}$, and then dipping the roots in a suspension of conidia $(10,000$ conidia/ml) for $30 \mathrm{~s}$. Control treatments were dipped in DI water for $30 \mathrm{~s}$. Root systems were then incubated for $1 \mathrm{~h}$ under damp paper towels at $25^{\circ} \mathrm{C}$. The rooted cuttings were then repotted with Miracle-Gro Potting Mix (Scotts Miracle-Gro Company, Marysville, $\mathrm{OH}$ ) in 16-oz. round plastic containers with holes punched in the bottom, and held for 4 weeks under grow lights with $12 \mathrm{~h}$ of light at room temperature $\left(22\right.$ to $\left.24^{\circ} \mathrm{C}\right)$. Sets of three rooted cuttings for each host were inoculated in replicates of three. Two weeks after inoculation, presence or absence and severity of crown rot symptoms were evaluated for each rooted cutting. Crown rot severity was measured by the length cankers grew up the crown (distance from the potting mix surface to the top of cankers). After 4 weeks, the entire root systems of all treatments were removed from the soil, rinsed under a stream of tap water for $30 \mathrm{~s}$, surface sterilized in $0.25 \% \mathrm{NaOCl}$ for $30 \mathrm{~s}$, and incubated in a petri plate with PEDA. After incubation at 22 to $24^{\circ} \mathrm{C}$ for 7 days, the presence of sporulation of $C$. pseudonaviculata on the root systems was evaluated with the aid of a dissecting microscope. Directly after roots were removed from the soil, a reading was taken on the percent symptomatic root tissue (necrotic or discolored root tissue) for each rooted cutting. A root rot severity rating index (Little and Hills 1978) was also used to evaluate the inoculated roots, where $0=$ asymptomatic, $1=1$ to $10 \%$ of the entire root system was symptomatic, $2=11$ to $35 \%$ symptomatic, $3=36$ to $65 \%$ symptomatic, $4=66$ to $90 \%$ symptomatic, and $5=91$ to $100 \%$ symptomatic. The experiment was repeated once.

To inoculate rooted cuttings by drenching, cuttings of $B$. sempervirens Arborescens ( 6 to $8 \mathrm{~cm}$ in length) were rooted as described above. Roots were inoculated by pipetting $0,0.1,10,12$, and $40 \mathrm{ml}$ of a conidial suspension $(1,000$ or 50,000 conidia $/ \mathrm{ml})$ onto the surface of the potting mix, resulting in $0,5,500,30,000$, and 100,000 conidia/g (dw) of potting mix. After adding conidia to the potting mix, each rooted cutting was watered with $50 \mathrm{ml}$ of DI water to wash the conidia into the root zone. Care was taken when watering the plants to avoid splashing conidia onto the stem or foliage of the plants. The cuttings were evaluated for crown rot every 7 days for 5 weeks. After 5 weeks, the entire root systems were removed from the potting mix, rinsed, surface sterilized, and evaluated for root infections by $C$. pseudonaviculata as described above. The seedlings were maintained under the same light and temperature conditions described above. Sets of five rooted cuttings per treatment were replicated three times for each inoculum dose. The experiment was repeated once.

Statistical analysis. Descriptive statistics were calculated, summarized, and graphed using Microsoft Excel. Further analysis was performed using JMP (SAS Institute, Cary, NC). For the bare root 
dipping root inoculation study, the severity of root and crown rot among $B$. harlandii, $B$. microphylla, $B$. sinica, and $B$. sempervirens was based on four different sets of measurements. These included (i) occurrence of dark lesions (binary outcome) at day 14, (ii) size of dark lesion (continuous outcome in $\mathrm{mm}$ ) at day 14 , (iii) root disease percentage assessed at day 30 (continuous outcome in percentage), and (iv) a root disease rating (categorical outcome from 1 to 5) at day 30. Thus, three statistical models were used to test for statistical difference. The logistic regression model was used to test for statistical difference in the presence or absence of crown rot or dark lesions at the base of seedlings among species, and the Kruskal-Wallis test was used to test for overall statistical difference for comparing both crown rot severity (lesion size) and disease percentage. The Dunn's Method for pairwise comparisons was used to test for statistical differences among host species when comparing crown rot severity (lesion size and disease percentage). The $\chi^{2}$ test of independence was used to test for statistical differences among species for the root disease ratings.

\section{Results}

Microsclerotia formation in inoculated leaf and root tissue of Buxus spp. Microsclerotia were formed in the leaves of all Buxus spp. and cultivars within 2 weeks of being inoculated. No microsclerotia were observed in control plants. Numbers of microsclerotia continued to increase until week 3 for all species and cultivars tested, with the exception of $B$. sempervirens Arborescens, which continued to form more microsclerotia until week 4 . High standard deviation was observed for the number of microsclerotia formed in the leaves of all Buxus spp. and cultivars at the sampling scale used in this study of $1 \mathrm{~mm}^{2}$ due to dense clumping of microsclerotia within leaves (Fig. 1).

C. pseudonaviculata was not observed sporulating from any of the root samples collected from diseased plants in the field. Sporulation and microsclerotia of $C$. pseudonaviculata were observed only from

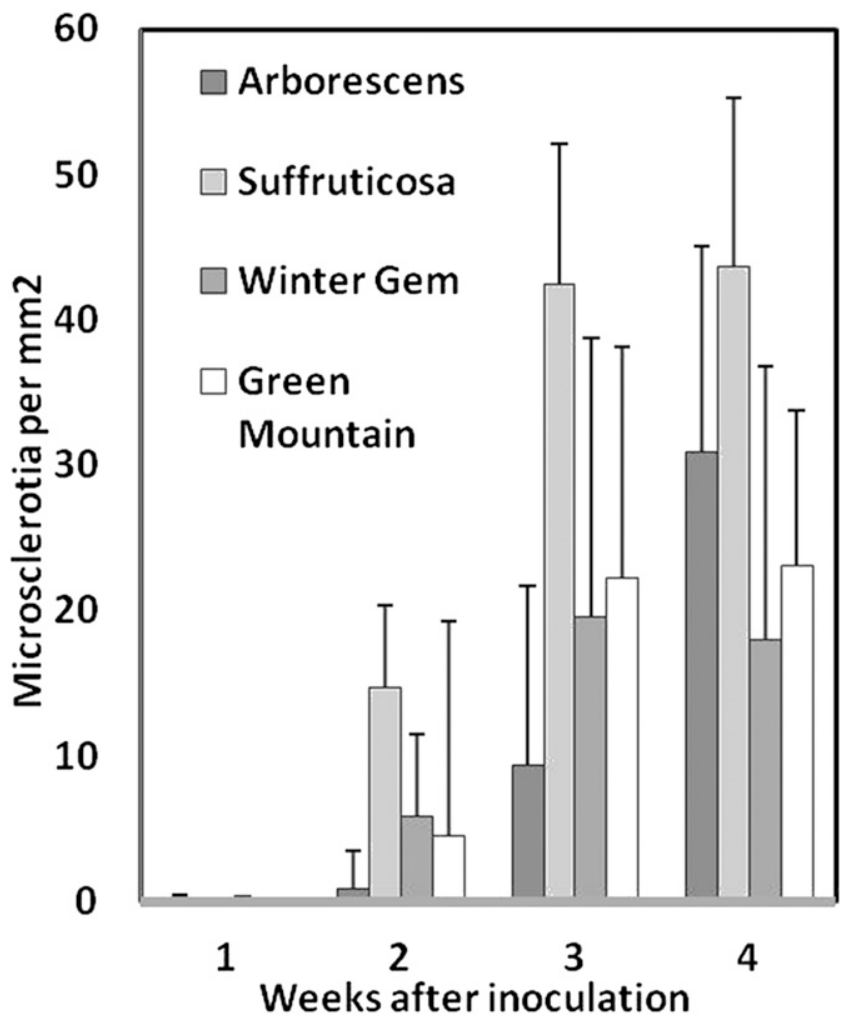

Fig. 1. Average number of microsclerotia formed by Calonectria pseudonaviculata in leaf tissue $\left(1-\mathrm{mm}^{2}\right.$ plots) in four Buxus cultivars for 4 weeks after initial inoculation. Error bars show standard deviation of data from two experiments in which microsclerotia were counted in three arbitrarily positioned $1-\mathrm{mm}^{2}$ areas on 7 to 10 arbitrarily chosen leaves from each cultivar for each week of the experiment. the root system of a single rooted cutting inoculated at the 100,000 conidia/g dose using the soil drench method. The roots of all four of the species and cultivars of Buxus that were inoculated in the lab using the root-dipping method became infected and sporulated with C. pseudonaviculata (as discussed in more detail in the results below). Microsclerotia were observed microscopically in roots of all species and cultivars of Buxus that were inoculated and became infected. Microsclerotia were associated with necrotic root tissue that developed sporulation of C. pseudonaviculata after incubation. Microsclerotia observed in both leaves and roots ranged in size from approximately 50 to $400 \mu \mathrm{m}$ in diameter but a majority were 100 to $250 \mu \mathrm{m}$ in diameter. Based on microscopic observation, microsclerotia were

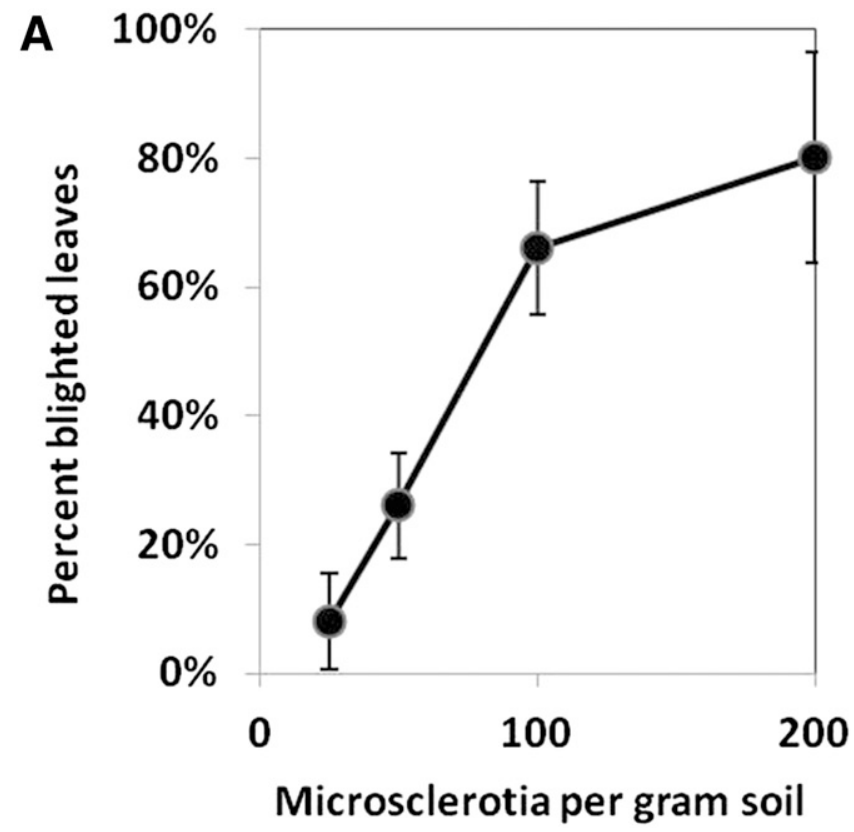

B

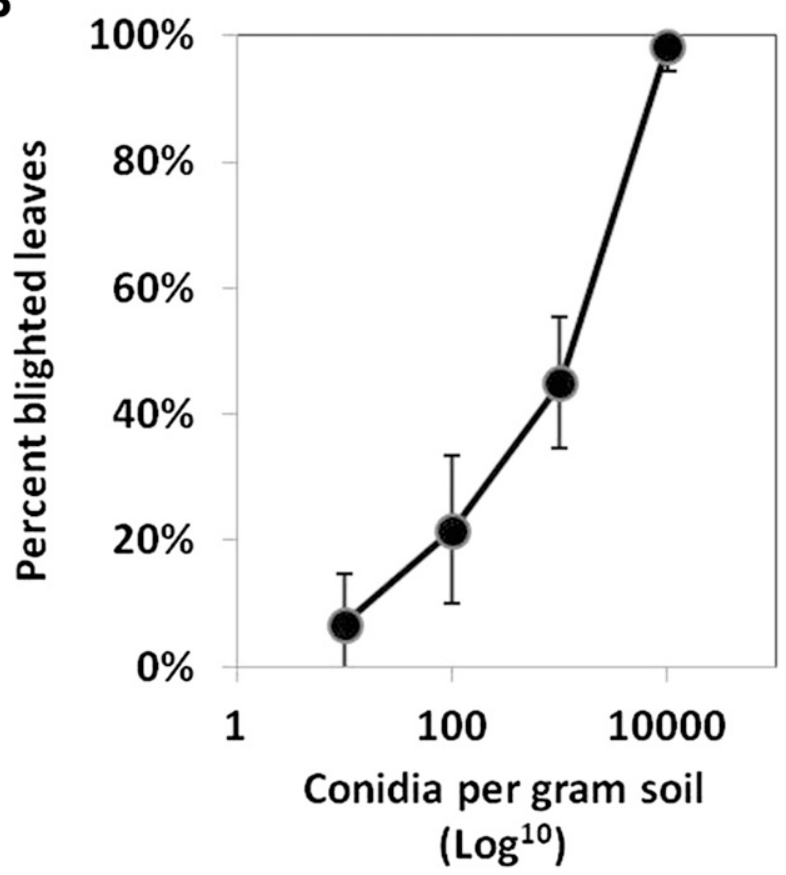

Fig. 2. A, Percent leaf blight caused by Calonectria pseudonaviculata 7 days after soil infested with varying concentrations of microsclerotia was applied to shoots of boxwood. B, Percent leaf blight caused by C. pseudonaviculata 7 days after soil infested with conidia was applied to shoots. Error bars show standard deviation of the mean, with four replicate shoots for each treatment from two experiments. 
frequently associated with and appeared to form under stomata in leaves.

Ability of soil infested with conidia and microsclerotia to cause foliar blight. Soil infested with microsclerotia and conidia consistently caused leaf blight with sporulation of $C$. pseudonaviculata when applied to cuttings of $B$. sempervirens (Arborescens). A positive correlation was consistently observed between concentration of microsclerotia and conidia and the percentage of leaves that became blighted (Fig. 2). Control treatments did not develop leaf blight or sporulation of $C$. pseudonaviculata.

Viability of microsclerotia and conidia in soil over time. C. pseudonaviculata was consistently isolated from soil infested with microsclerotia for 40 weeks using a leaf disc bioassay. The leaf disc recovery rate of $C$. pseudonaviculata remained relatively high and consistent from soil infested with microsclerotia. C. pseudonaviculata was recovered from soil infested with conidia for 3 weeks. The recovery rate of $C$. pseudonaviculata from soil infested with conidia decreased rapidly after 1 week (Fig. 3). After 8 weeks, we stopped attempting to recover $C$. pseudonaviculata from soil infested with conidia.

Potential for $C$. pseudonaviculata to cause crown and root rot. Two weeks after inoculating roots using the root-dipping method, $59 \%$ of B. sempervirens Arborescens, $83 \%$ of B. microphylla Winter Gem, $89 \%$ of $B$. sinica Wintergreen, and $11 \%$ of $B$. harlandii developed crown rot (Fig. 4). None of the controls developed symptoms of crown rot. Crown rot was expressed as necrosis at the crown and formation of long, dark cankers that grew up the stem, often above the level to which the root systems had been dipped in a conidial suspension (Fig. 5). The logistic regression model indicated that significantly fewer $B$. harlandii developed crown rot compared with $B$. sempervirens, $B$. microphylla, and $B$. sinica $(P<0.0035, P<0.0037$, and $P<0.0035$, respectively). The severity of crown rot, measured as the average length that cankers extended up the from the crown of rooted cuttings at 2 weeks, was $2.52 \mathrm{~mm}$ for B. sempervirens Arborescens, $3.44 \mathrm{~mm}$ for B. microphylla Winter Gem, $2.28 \mathrm{~mm}$ for $B$. sinica Wintergreen, and $0.11 \mathrm{~mm}$ for B. harlandii (Fig. 4). Using the Kruskal-Wallis test, an overall statistical difference was observed for the average length of cankers that formed among the inoculated cultivars $(P<0.0001)$. Based on the Dunn's Method for pairwise comparisons, cankers formed on $B$. harlandii were significantly shorter than those formed on $B$. sempervirens, B. microphylla, and B. sinica $(P<0.0001, P<0.0001$, and $P=0.0063$, respectively). At 4 weeks, all of the rooted cuttings that were inoculated developed symptoms of root rot while the controls remained asymptomatic (Fig. 5). Based on the $\chi^{2}$ test of independence indicated, B. sempervirens Arborescens and B. microphylla Winter Gem had a significantly higher root rot severity rating than $B$. sinica Wintergreen and $B$. harlandii $(P<0.0001$ and $P=0.0003$, respectively; Fig. 4). This same trend $(P<$ 0.0001 and $P<0.0001$, respectively) was observed based on estimated percent necrotic and discolored root tissue readings (data not shown). All of the inoculated rooted cuttings developed sporulation of $C$. pseudonaviculata from necrotic and discolored root tissue after incubating the root systems for 7 days (Fig. 6). Sporulation of $C$. pseudonaviculata was not observed from control plants.

Using the drenching method, 59 and $32 \%$ of the B. sempervirens Arborescens treated with 100,000 and 30,000 conidia/g (dw) of potting mix, respectively, 2 weeks after inoculation developed crown rot. None of the rooted cutting developed crown rot at the lower dose levels using the soil-drench method (Fig. 7). Sporulation of C. pseudonaviculata was observed only from the root system of a single rooted cutting at the 100,000 conidia/g dose using the drenching inoculation method.

\section{Discussion}

In this study, we observed experimentally that the boxwood blight pathogen $C$. pseudonaviculata consistently forms microsclerotia in artificially inoculated leaves of some of the most commonly planted and grown Buxus spp. Microsclerotia are resting propagules that allow pathogens to persist in soil and cause subsequent disease to host plants (Crous 2002). The surface area of one side of a $B$. sempervirens Suffruticosa leaf is approximately $80 \mathrm{~mm}^{2}$. Using this estimate of leaf area, an infected leaf could contain as many as 3,600 microsclerotia based on the average number of microsclerotia we counted in B. sempervirens Suffruticosa leaf tissue 4 weeks after inoculation. This means 1,000 infected leaves could potentially harbor and eventually introduce as many as 3.6 million microsclerotia to a site if not removed or destroyed before they decompose, releasing microsclerotia into the soil. It is common to see plants with boxwood blight drop thousands of infected leaves onto the soil in the field.

Along with producing large numbers of microsclerotia in leaf tissue, we observed that soil infested with conidia and microsclerotia can cause foliar blight to boxwood and that these propagules can remain viable in soil for up to 3 and at least 40 weeks, respectively. These observations provide further evidence that $C$. pseudonaviculata has the potential to have an epidemiologically significant soil phase. We have observed experimentally that all the components are present for infested soil to serve as a reservoir of viable propagules by which new epidemics of foliar blight can initiate when infested soil is splashed onto foliage from the ground during rain or irrigation events. This may help explain why, at the early stages of boxwood blight, we commonly observe symptoms at the base of plants where soil has splashed onto the lower foliage in the field. Our data also suggest a potential for pathogen inoculum to be spread

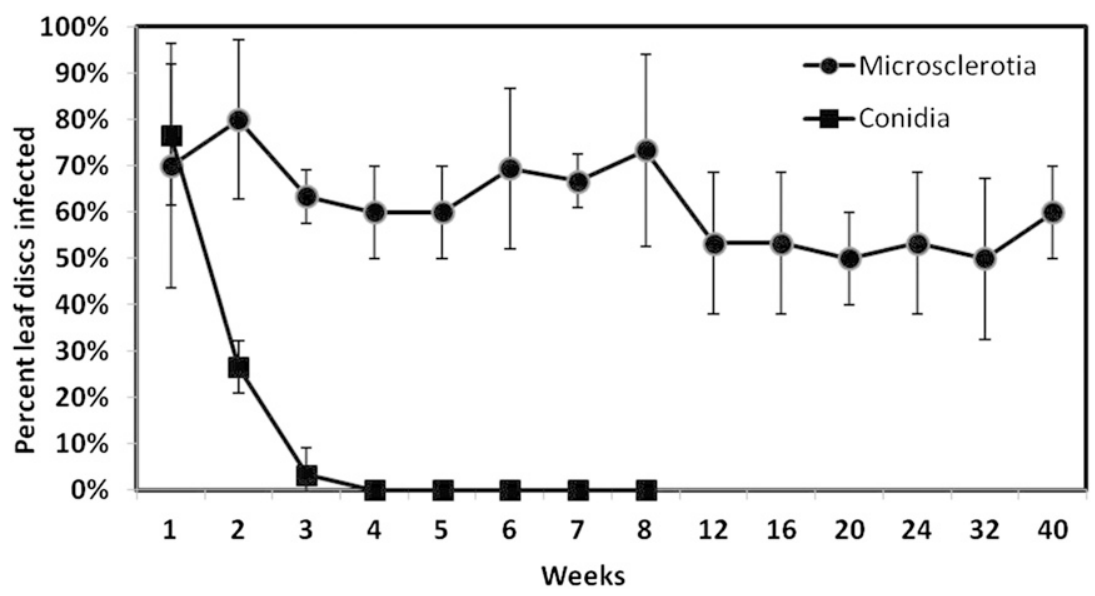

Fig. 3. Survival of conidia and microsclerotia in soil as indicated by the percent leaf discs infected with Calonectria pseudonaviculata using a leaf disc bioassay. Error bars show standard deviation of the mean, with three replicates for each treatment from two experiments. 
on soiled pots, vehicles, boots, and tools. Measures such as destroying fallen leaf debris using agricultural flamers (Dart et al. 2012) and cleaning and sanitizing tools and equipment that come into contact with potentially infested soil should be included in bestmanagement practices for boxwood blight.

In this study we, observed that microsclerotia can remain viable in soil longer than conidia. C. pseudonaviculata could only be recovered from soil infested with conidia for 3 weeks whereas the pathogen could be recovered from soil infested with microsclerotia for at least 40 weeks. Previous work has reported that conidia of C. crotalaria can remain viable in soil for up to 32 weeks (Hwang and Ko 1976), substantially longer than what we observed for C. pseudonaviculata under similar experimental conditions. Although conidia of $C$. pseudonaviculata survive a relatively short time in soil, the observation that conidia can remain viable in soil for 3 weeks may be of epidemiological significance. At sites where the pathogen has
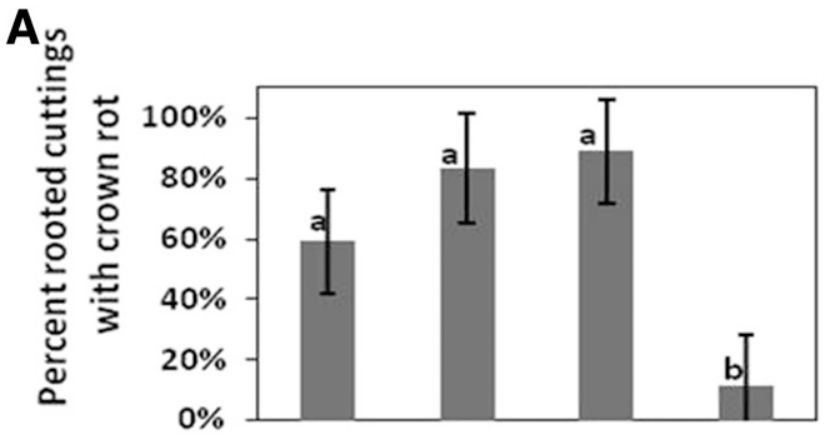

B

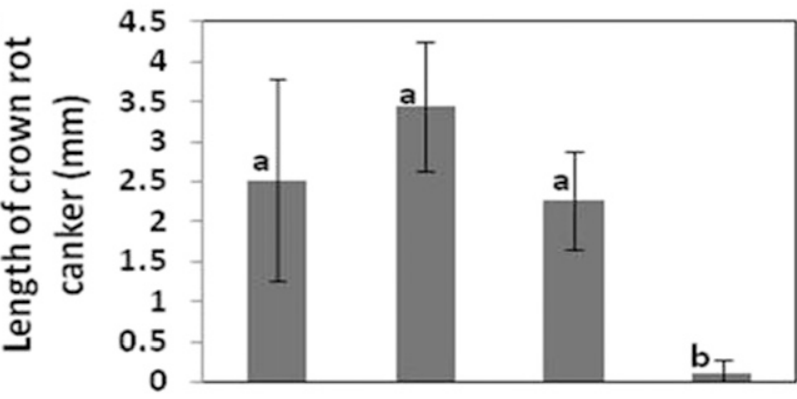

C

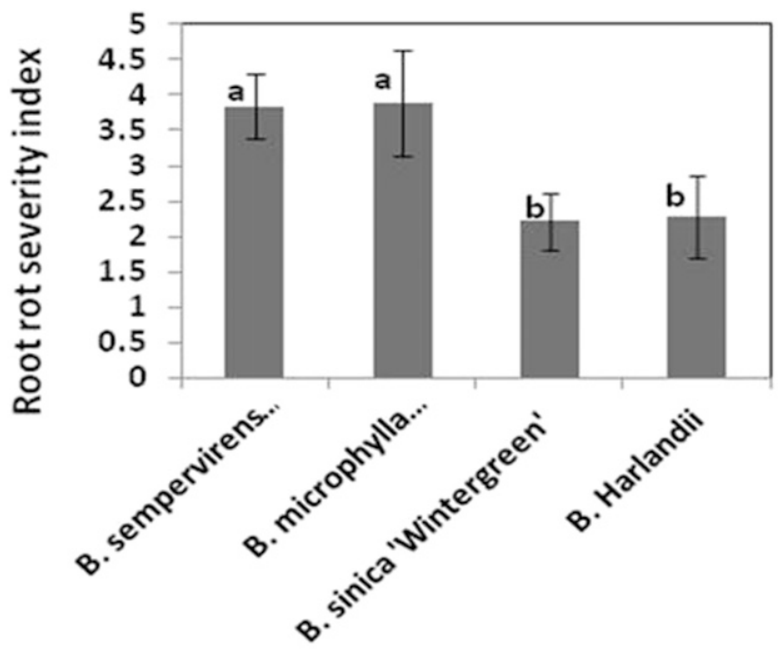

Fig. 4. A, Percent rooted cuttings that developed crown rot 2 weeks after inoculation with Calonectria pseudonaviculata using the root-dipping method. B, Crown rot severity measured as length of cankers extending up stem of rooted cuttings that developed crown rot 2 weeks after inoculation using the root-dipping method. C, Root rot severity index 4 weeks after inoculation using the root-dipping method. Error bars for all figures show the standard deviation of two experiments, each consisting of three replicates of three rooted cuttings. Statistical differences among varieties are indicated by a different letter. recently been introduced, even soil that does not appear to have leaf debris potentially containing microsclerotia could harbor and transport viable conidia for up to 3 weeks. This has management implications and underlines the importance of cleaning and sanitizing

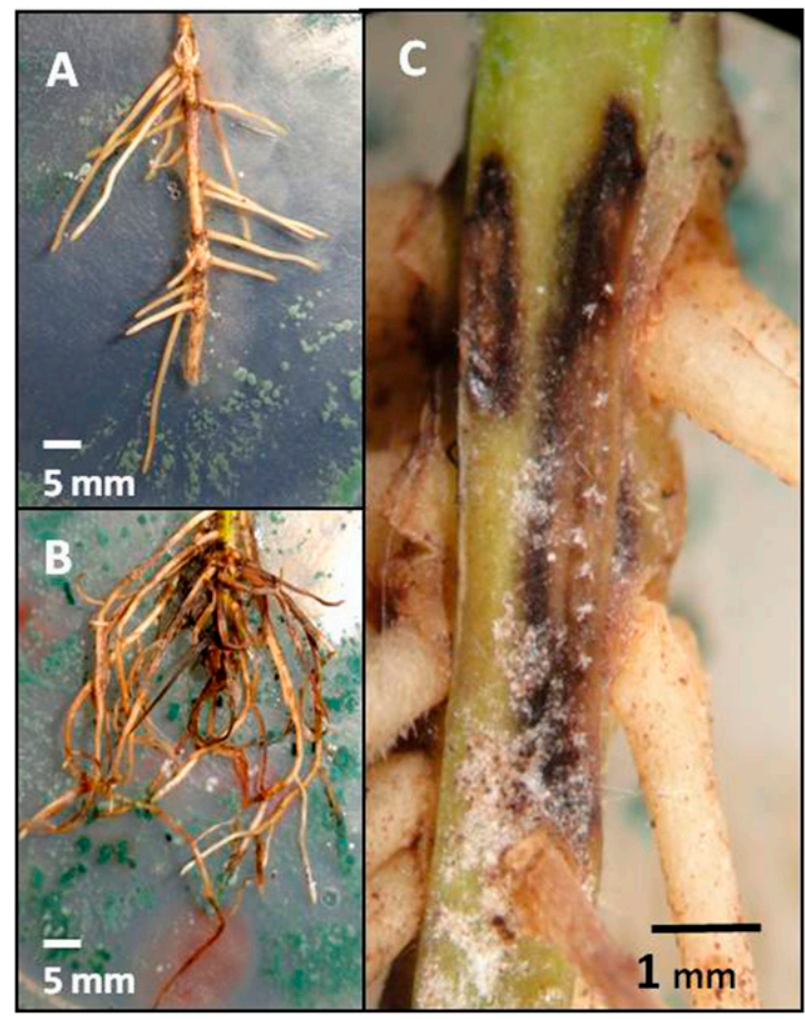

Fig. 5. Root systems of Buxus sempervirens 'Arborescens'. A, Control that remained asymptomatic; $\mathbf{B}$, root system that developed root rot after inoculation with Calonectria pseudonaviculata using the root-dipping method; $\mathbf{C}$, crown rot on rooted cutting that developed after inoculation with a conidia suspension. Note sporulation of $C$. pseudonaviculata from necrotic tissue and the development of dark, elongated cankers.

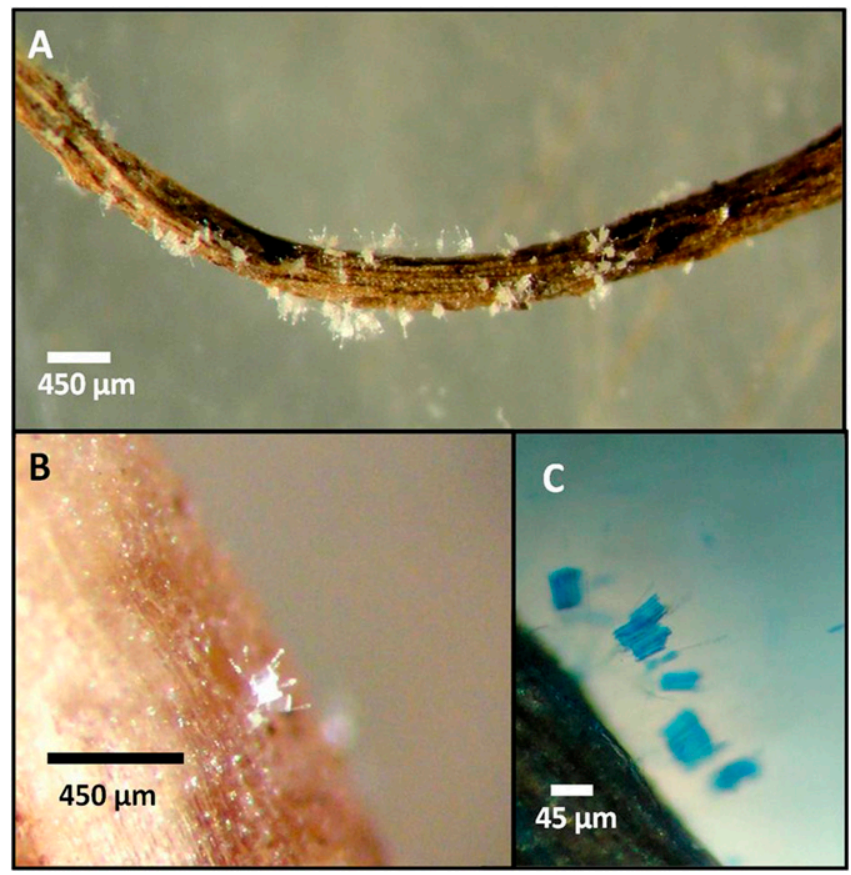

Fig. 6. A, B, and C, Sporulation of Calonectria pseudonaviculata from roots of Buxus sempervirens 'Arborescens' inoculated using the root-dipping method. 


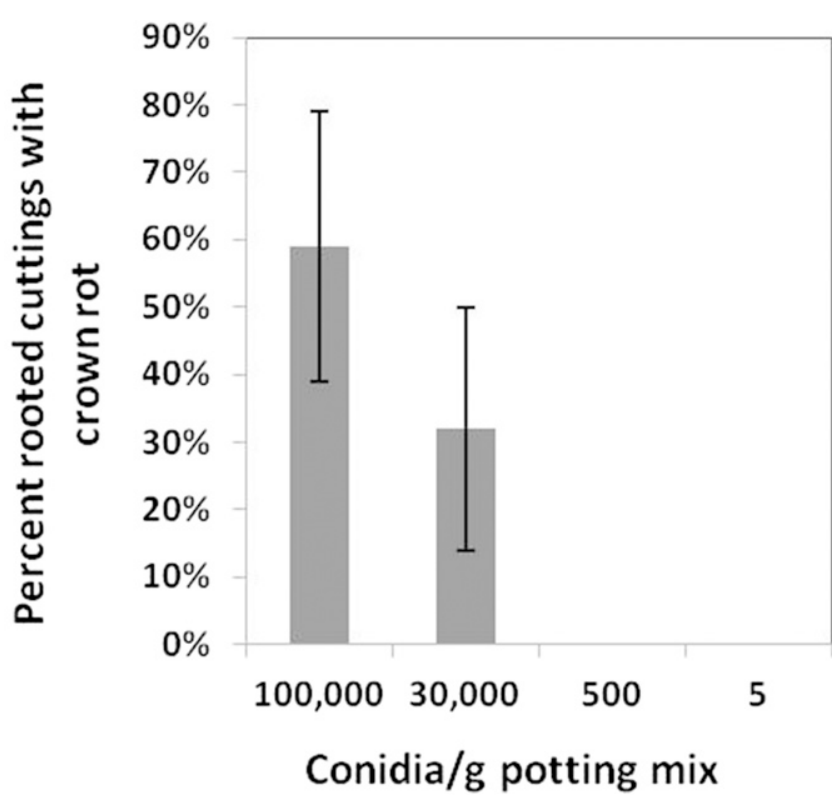

Fig. 7. Percent rooted cuttings (Buxus sempervirens 'Arborescens') that developed crown rot 2 weeks after inoculation with Calonectria pseudonaviculata using the drenching method. Error bars show standard deviation of two experiments with three replicates of five rooted cuttings within an experiment.

equipment after working with potentially infested soil apparently free of leaf debris at sites where boxwood blight is present.

Based on other studies that have looked at survival (ability of microsclerotia to sporulate) of Calonectria microsclerotia, C. pseudonaviculata is likely able to survive substantially longer than 40 weeks in soil. Microsclerotia of other Calonectria spp. have been reported to survive as long as 15 years in field soil (Crous 2002; Sobers and Littrell 1974; Thies and Patton 1970). Additionally, we looked at survival under what we would consider optimal conditions for survival (moist soil at moderate temperatures). Future studies should look at survival over varying temperature and soil moisture conditions.

This study also demonstrated that $C$. pseudonaviculata can cause root and crown rot to Buxus spp. and there are differences in resistance to root rot among the hosts tested. We observed root rot consistently when dipping roots directly into a suspension of conidia but not when drenching inoculum suspensions onto potting mix. Root infection was only observed in one instance by drenching potting mix with conidia, and never in the field. These observations suggest that high levels of $C$. pseudonaviculata inoculum must come into direct contact with roots of plants for root rot to develop. Based on our field surveys, root infections by $C$. pseudonaviculata do not currently appear to be an issue for growers. This may be because high levels of inoculum are not coming into contact with the crowns and roots of plants under field conditions. Perhaps conidia of this pathogen do not effectively filter though the soil to reach the roots. Alternatively, perhaps the pathogen is simply not an aggressive root pathogen and has evolved to specialize as a foliar pathogen. Future investigations into root infection in the field should be focused on locations where inoculum pressure is high, such as sites where the pathogen has been present for several years and has had time to build up inoculum levels in the soil. Future laboratory studies could investigate potential differences in spore germination when conidia and microsclerotia are exposed to exudates from roots versus foliage.

\section{Acknowledgments}

Funding support was provided from the 2008 Farm Bill for the fy 13 project (138130-0282-CA) and the 2014 Farm Bill for the fy14 project (14-8130-0282-CA) through the Animal and Plant Health Inspection Service.

\section{Literature Cited}

Black, M. C., and Beute, M. K. 1985. Soil components that affect the severity of Cylindrocladium black rot on peanuts. Plant Dis. 69:36-39.

Crous, W. P. 2002. Pathogenicity and microsclerotia. Pages 8-12 in: Taxonomy and Pathology of Cylindrocladium and Allied Genera. American Phytopathological Society, St. Paul, MN.

Dart, N. L., Arrington, S. M., and Weeda, S. M. 2012. Flaming to reduce inocula of the boxwood blight pathogen, Cylindrocladium pseudonaviculatum in field soil. Online publication. Plant Health Prog. doi:doi:10.1094/PHP2012-1026-01-BR

Dart, N. L., Hong, C., and Bradley, W. T. 2014. An improved leaf disc bioassay for detecting Calonectria pseudonaviculata in soil and potting media. Plant Dis. 98:1626-1631.

Gonçalves, R. C., Alfenas, A. C., Maffia, L. A., and Crous, P. W. 2001. Evaluation of bioassays to quantify Cylindrocladium inocula in soil. Mycoscience 42: 261-264.

Henricot, B., and Culham, A. 2002. Cylindrocladium buxicola, a new species affecting Buxus spp., and its phylogenetic status. Mycologia 94:980-997.

Henricot, B., Gorton, C., Denton, G., and Denton, J. 2008. Studies on the control of Cylindrocladium buxicola using fungicides and host resistance. Plant Dis. 92 1273-1279.

Hwang, S. C., and Ko, W. H. 1975. A medium for enumeration and isolation of Calonectria crotalariae from soil. Phytopathology 65:1036-1037.

Hwang, S. C., and Ko, W. H. 1976. Biology of conidia, ascospores, and microsclerotia of Calonectria crotalariae in soil. Phytopathology 66 51-54.

Ivors, K. L., Lacey, L. W., Milks, D. C., Douglas, S. M., Inman, M. K., Marra, R. E., and LaMondia, J. A. 2012. First report of boxwood blight caused by Cylindrocladium pseudonaviculatum in the United States. Plant Dis. 96: 1070.

Kuruppu, P. U., Schneider, R. W., and Russin, J. S. 2004. Effects of temperature on microsclerotia of Calonectria ilicicola and soybean root colonization by this fungus. Plant Dis. 88:620-624.

Linderman, R. G. 1972. Isolation of Cylindrocladium from soil or infected azalea stems with azalea leaf traps. Phytopathology 62:736-739.

Linderman, R. G. 1973. Formation of microsclerotia of Cylindrocladium spp. in infected azalea leaves, flowers, and roots. Phytopathology 63:187-191.

Little, T. M., and Hills, F. J. 1978: Page 350 in: Agricultural Experimentation Design and Analysis. John Wiley and Sons, New York.

Phipps, P. M., Beute, M. K., and Barker, K. R. 1976. An elutriation method for quantitative isolation of Cylindrocladium crotalariae microsclerotia from peanut field soil. Phytopathology 66:1255-1259.

Rowe, R. C., Johnston, S. A., and Beute, M. K. 1974. Formation and Dispersal of Cylindrocladium crotalariae Microsclerotia in Infected Peanut Roots. Phytopathology 64:1294-1297.

Sobers, E. K., and Littrell, R. H. 1974. Pathogenicity of three species of Cylindrocladium to select hosts. Plant Dis. Rep. 58:1017-1019.

Thies, W. G., and Patton, R. F. 1970. The biology of Cylindrocladium scoparium in Wisconsin forest tree nurseries. Phytopathology 60:1662-1668.

Weeda, S. M., and Dart, N. L. 2012. Histological evidence that microsclerotia play a significant role in disease cycle of the boxwood blight pathogen, Cylindrocladium pseudonaviculatum, in Southeastern United States and implications for disease mitigation. Online publication. Plant Health Prog. doi:doi:10.1094/PHP2012-0403-01-BR 